\title{
Neonatal Natural Killer Cell Function: Relevance to Antiviral Immune Defense
}

\author{
Yen-Chang Lee ${ }^{1}$ and Syh-Jae Lin ${ }^{2}$ \\ ${ }^{1}$ Department of Obstetrics/Gynecology, Chang Gung Memorial Hospital, Taoyuan 333, Taiwan \\ ${ }^{2}$ Division of Asthma, Allergy, and Rheumatology, Department of Pediatrics, Chang Gung Children's Hospital, College of Medicine, \\ Chang Gung University, Taoyuan 333, Taiwan \\ Correspondence should be addressed to Syh-Jae Lin; sjlino@cgmh.org.tw
}

Received 17 June 2013; Revised 19 July 2013; Accepted 25 July 2013

Academic Editor: Mario Clerici

Copyright (C) 2013 Y.-C. Lee and S.-J. Lin. This is an open access article distributed under the Creative Commons Attribution License, which permits unrestricted use, distribution, and reproduction in any medium, provided the original work is properly cited.

Neonates are particularly susceptible to various pathogens compared to adults, which is attributed in part to their immature innate and adaptive immunity. Natural killer cells provide first-line innate immune reactions against virus-infected cells without prior sensitization. This review updates phenotypic and functional deficiencies of neonatal cells compared to their adult counterparts and their clinical implications.

\section{Introduction}

Natural killer (NK) cells are a distinct lineage of lymphoid cells defined by the expression of CD56 and NKp46 and by the absence of $\mathrm{CD} 3$, providing the first-line defense by lysing tumor and virus-infected cells in a nonmajorhistocompatibility-complex- (MHC-) restricted fashion without the need of prior sensitization [1-4]. Receptors commonly expressed on NK cell surface include killer immunoglobulin-like receptors (KIR), heterodimeric Ctype lectin receptors which can be inhibitory (NKG2A) or activating (NKG2C and NKG2D), and natural cytotoxicity receptors (NCR) [5-8].

NK cells can perform antibody-dependent cellular cytotoxicity (ADCC) through CD16 [9] or directly exert their cytotoxic ability by the release of perforin and granzyme B $[1,3,10]$. NK cells also kill tumor and virus-infected cells by apoptosis, mediating through TNF-related apoptosisinducing ligand (TRAIL) and FasL [11].

NK cells also produce many cytokines such as interleukin (IL)-5, IL-10, IL-13, GM-CSF, TNF- $\alpha$, TGF- $\beta$, and IFN- $\gamma$ $[8,12]$. IFN- $\gamma$ can induce $\mathrm{T}_{\mathrm{H}} 1$ responses and also up-regulate MHC-I expression on antigen presenting cells. Recent pieces of evidence suggest the greater regulatory roles for NK cells by bridging innate with adaptive immunity via their intimate interactions with dendritic cells, B cells, and T cells [1315]. Human NK cells can be divided into two major subsets based on CD56 expression: the CD56 ${ }^{\mathrm{dim}}$ subset accounts for the majority (>90\%) of peripheral blood NK cells that are more effective at mediating cytotoxic function, while the $\mathrm{CD} 56^{\text {bright }} \mathrm{CD} 16^{\text {dim }}$ subset, characterized by the ability to produce immunoregulatory cytokines, constitutes only a minority $(<10 \%)$ of the total NK cells $[1,8]$.

\section{Immunophenotype of Neonatal Natural Killer Cells}

Human neonates have comparable or higher numbers and percentages of $\mathrm{NK}\left(\mathrm{CD} 56^{+} / \mathrm{CD}^{+} 6^{+} / \mathrm{CD}^{-}\right)$cells in their peripheral blood compared to adults [16-18]. Gaddy and Broxmeyer showed that the $\mathrm{CD} 56^{-} \mathrm{CD} 16^{+}$subset NK cells are more abundant in the neonates and are precursors of the more mature $\mathrm{CD} 56^{+} \mathrm{CD} 16^{+} \mathrm{NK}$ cells [19]. The CD56 ${ }^{\text {bright }}$ and CD56 ${ }^{\mathrm{dim}} \mathrm{NK}$ cell subsets are present in similar proportions in neonatal blood and adult blood [20, 21]. Very few neonatal NK cells express CD57, a marker of terminal differentiation [21]. CD $57^{+} \mathrm{NK}$ cells are characterized by a higher cytotoxic capacity but decreased cytokine responsiveness [22]. Neonatal NK cells express lower L-selectin (CD62L) compared 
to adults $[20,23]$, highlighting their unique lymph node homing properties. We and others have found a lower level of CD54 expression on neonatal NK cells [24, 25], suggesting an impaired ability to adhere to target cells. We observed a higher NKp46 expression in neonatal NK cells compared to adults [26]. The level of expression of other triggering receptors like NKp30, NKG2D, and NKG2A/CD94 decreases with age $[27,28]$.

\section{Neonatal Natural Killer Cytotoxic Function}

We and others have shown that neonatal NK cells show less NK cell cytotoxicity and ADCC than their adult peripheral blood (APB) counterparts, respectively [9, 20, 29-31]. Several possibilities contribute to the impaired cytotoxicity of neonatal NK cells. First, neonatal NK cells form fewer NKtarget cell conjugations compared with adult NK cells [21]. Secondly, compared with adult NK cells, neonatal NK cells express lower levels of adhesion molecules like L-selectin and CD54 [25, 32]. In contrast, the expression of inhibitory receptors, such as CD94/NKG2A, was higher on neonatal NK cells than those on adult NK cells [28]. Finally, neonatal NK cells exhibit an impaired F-actin polymerization in forming immunologic synapses with leukemic cells, a defect that could be reversed with IL-2 [33]. Interestingly, the level of expression of NK cytotoxic machinery such as perforin and granzyme B by neonatal NK cells was comparable to or even higher than APB NK cells $[20,33]$. We observed that neonatal NK cells were less susceptible to K562-induced apoptosis than adult NK cells [34].

\section{Cytokine Production of Neonatal NK Cells}

NK cells serve as a bridge between innate immunity and adaptive immunity and release a variety of cytokines such as GM-CSF, TNF- $\alpha$, and IFN- $\gamma$ and chemokines like MIP- $1 \alpha$, MIP-1 $\beta$, and RANTES that modulate the subsequent adaptive immune response. Krampera et al. reported that neonatal NK cells showed a lower percentage of TNF- $\alpha$ producing cells compared to adult NK cells [35]. We and others have shown that resting neonatal NK cells did not produce IFN- $\gamma$ $[26,36]$. However, neonatal NK cells exhibited higher IFN$\gamma$ production and CD69 expression than APB NK cells after stimulation with IL-12 and IL-18 [37].

\section{Neonatal NK Cell Response to Viral Infections}

NK cells play a critical role of controlling most viral infections [38]. NK cells emerge as an effective, early defense against viral infections by mediating cytotoxicity and cytokine production [39, 40]. As previously stated, the CD56 ${ }^{\mathrm{dim}} \mathrm{NK}$ subset is more cytotoxic, while the CD56 ${ }^{\text {bright }}$ subset mainly produces cytokines that serve as immuneregulators $[8,41]$.

A series of interactions between viruses and surface receptors on NK cells are critical in activating antiviral NK defense. The NCRs like NKp46, NKp30 and NKp44, and NKG2D are essential in NK cell activation, while the inhibitory NK receptors like p58.1, p58.2, p70, NKG2A, and LIR-1 provide negative signals that allow $\mathrm{NK}$ cells to discriminate between normal cells and cells that have lost their MHC-I molecules [42-44]. NKp46 is the major triggering receptor involved in the natural cytotoxicity of human NK cells and binds hemagglutinin of influenza virus $[45,46]$, while NKG2A and NKp30 are involved in interaction with dendritic cells that shape subsequent T-cell response $[47,48]$.

NK cells are activated during the initial stages of viral infections by cytokines and chemokines, including IFN- $\alpha$, IFN- $\beta$, IL-12, IL-15, and IL-18, produced by infected cells or by activated dendritic cells and macrophages [49, 50]. Activated NK cells produce TNF- $\alpha$, IFN- $\gamma$, GM-CSF, and chemokines that are significant in the noncytolytic control of viral infections and may help shape the subsequent adaptive immune response. The number of NK cells in the liver during mouse cytomegalovirus (CMV) infection was decreased in MIP-1 $\alpha$-deficient mice, suggesting that chemokines may play a crucial role in NK trafficking during viral infection [51]. The chemokine-dependent recruitment of NK cells during viral infection is mediated by IFN $-\gamma$ [52].

The phenotypic and functional defects of neonatal NK cells may compromise their antiviral immune defense. Patients with primary NK cell deficiency are particularly susceptible to severe varicella and complicated herpes virus infections [53, 54]. Adult NK cells expressing an inhibitory receptor for self-MHC-I show enhanced effector function, the so called NK licensing [55-57]. NK cell repertoires in neonates are not yet shaped toward increased clonal frequency of KIR for self-MHC-I [58], contributing to their greater infection susceptibility.

Virus infection can induce modifications of the repertoire of NK cell receptors, notably CMV [59]. In vitro exposure to $\mathrm{CMV}$ leads to increased expression of the inhibitory receptors KIR2DL1 and KIR2DL3 only in CMV-seropositive donors [60]. Pediatric CMV infection is associated with the expansion of the CD94/NKG2C ${ }^{+} \mathrm{NK}$ cell subset [61].

Increased NK cell activity has been correlated with protection from human immunodeficiency virus (HIV) infection in highly exposed seronegative subjects [62]. We and others have shown the deficient NK and ADCC function of NK cells in the HIV-infected subjects [63-65]. Different KIR-HLA associations may determine susceptibility to HIV infection and the rate of disease progression [66]. Ballan et al. observed an increased frequency of NK cells expressing inhibitory KIR in HIV-infected children. The increased expression of KIR2DL3, NKG2C, and NKp46 on NK cells correlated with decreased $\mathrm{CD} 4^{+}$T-lymphocyte count [67]. HLA-C/KIR interactions may play a role in maintaining the immunity in HIV-infected long-term nonprogressors [68]. Increased KIR2DL3 expression of NK cells was associated with a full immunological recovery after effective antiretroviral therapy in HIV-infected subjects [69].

Immune activation of HIV leads to enhanced CCR5 expression on NK cells [70]. The chemokines MIP- $1 \alpha$, MIP$1 \beta$, and RANTES produced by NK cells bind to CCR 5 and inhibit HIV cell entry and replication [71]. Interestingly, Bernstein et al. reported that neonatal and adult NK cells 
produce comparable amounts of chemokines [72], while Jacobson et al. showed reduced expression of MIP- $1 \alpha$, MIP$1 \beta$, and RANTES in neonatal NK cells upon challenge of autologous HIV-infected $\mathrm{CD} 4^{+} \mathrm{T}$ cells [73].

Severe acute respiratory infections with influenza virus in infants are associated with reduced level of peripheral blood NK cells $[74,75]$. We and others have shown that influenza virus directly infects NK cells and induces their apoptosis [26, 76]. We further showed that influenza-A-induced apoptosis in neonatal NK cells was more pronounced than in adult NK cells [26], which may contribute to the greater morbidity of influenza-infected infants less than 6 months of age [77, 78 ], despite the possible protection provided by maternal antibodies.

\section{Interleukin-15 Enhances Neonatal NK Function}

IL-15, mainly produced by macrophages and monocytes, uses the common $\beta$ and $\gamma$ chains with the IL- 2 receptor and a unique $\alpha$ chain for binding and signal transduction [79]. IL-15 plays a pivotal role in NK differentiation and survival $[80,81]$. The interaction of IL-15 with its receptor complex on NK cells leads to a series of signaling including activation of Janus kinase (Jak)/signal transducer and activator of transcription (STAT) pathways, similar to that of IL-2 [82, 83]. IL-15 expression is significantly decreased at the gene and protein levels in neonatal mononuclear cells compared to APB mononuclear cells [84]. We and others have shown that neonatal NK cells rapidly acquire cytotoxic activity after IL15 stimulation, although this activity was still lower than correspondingly IL-15-treated adult NK cells [29, 31].

IL-15 is also capable of inducing antigen-independent expansion and differentiation of human naive and memory $\mathrm{CD}^{+} \mathrm{T}$ cells and enhances their replicative potential $[85,86]$. Administration of IL-15 results in increased antimicrobial activity in mice against herpes simplex virus (HSV) infection $[87,88]$ and enhances HIV-specific $\mathrm{CD}^{+}{ }^{+}$T-cell responses in HIV-infected subjects [89]. IL-15 may be used as an adjunct to antiretroviral therapy to bolster immune reconstitution in HIV-infected subjects [90]. The ability of IL-15 to activate both $\mathrm{NK}$ and $\mathrm{CD}^{+} \mathrm{T}$ cells makes it a potential effective immunotherapy for neonates with severe life-threatening viral infections.

\section{Conclusion}

Phenotypic and functional differences between neonatal and adult NK cells were highlighted in this paper. It is now known that different KIR-HLA combinations may modulate NK function and influence the progression of infectious diseases. NK cell repertoires of the neonates are not yet shaped toward increased clonal frequencies of KIR for self-HLA class I like that of the adults. The frequency of NK cells expressing cognate KIR for self-HLA class I may gradually increase from neonatal period to adulthood through certain viral infections. Further work will be needed to explore what triggers the transition from an unbiased neonatal KIR repertoire to a biased adult KIR repertoire and to elucidate how different KIR-HLA combinations contribute to the control of neonatal infections. Immunotherapy using NK-enhancing cytokines like IL-15 may benefit neonates with severe viral infections.

\section{Acknowledgments}

This paper was supported partially by Grants from National Science Council of Republic of China: NSC98-2314-B-182003-MY3, NSC97-2314-B-182-017, and NSC101-2314-B182033 and partially by Grants from Chang Gung Memorial Hospital: CMRPG460082, CMRPG460083, and CMRPG4A005153.

\section{References}

[1] M. A. Caligiuri, "Human natural killer cells," Blood, vol. 112, no. 3, pp. 461-469, 2008.

[2] J. S. Orange and Z. K. Ballas, "Natural killer cells in human health and disease," Clinical Immunology, vol. 118, no. 1, pp. 1-10, 2006.

[3] T. A. Fehniger, S. F. Cai, X. Cao et al., "Acquisition of murine NK cell cytotoxicity requires the translation of a pre-existing pool of granzyme B and perforin mRNAs," Immunity, vol. 26, no. 6, pp. 798-811, 2007.

[4] A. Diefenbach, E. R. Jensen, A. M. Jamieson, and D. H. Raulet, "Rael and H60 ligands of the NKG2D receptor stimulate tumour immunity," Nature, vol. 413, no. 6852, pp. 165-171, 2001.

[5] D. Pende, C. Cantoni, P. Rivera et al., "Role of NKG2D in tumor cell lysis mediated by human NK cells: cooperation with natural cytotoxicity receptors and capability of recognizing tumors of nonepithelial origin," European Journal of Immunology, vol. 31, pp. 1076-1086, 2001.

[6] A. Moretta, C. Bottino, M. C. Mingari, R. Biassoni, and L. Moretta, "What is a natural killer cell?" Nature Immunology, vol. 3, no. 1, pp. 6-8, 2002.

[7] L. L. Lanier, "NK cell recognition," Annual Review of Immunology, vol. 23, pp. 225-274, 2005.

[8] M. A. Cooper, T. A. Fehniger, S. C. Turner et al., "Human natural killer cells: a unique innate immunoregulatory role for the CD56bright subset," Blood, vol. 97, no. 10, pp. 3146-3151, 2001.

[9] Q. H. Nguyen, R. L. Roberts, B. J. Ank, S.-J. Lin, E. K. Thomas, and E. R. Stiehm, "Interleukin (IL)-15 enhances antibodydependent cellular cytotoxicity and natural killer activity in neonatal cells," Cellular Immunology, vol. 185, no. 2, pp. 83-92, 1998.

[10] S.-J. Lin and M.-L. Kuo, "Cytotoxic function of umbilical cord blood natural killer cells: relevance to adoptive immunotherapy," Pediatric Hematology and Oncology, vol. 28, no. 8, pp. 640646, 2011.

[11] Y. Zhang, G. Cheng, Z. W. Xu et al., "Down regulation of TRAIL and FasL on NK cells by Cyclosporin A in renal transplantation patients," Immunology Letters, vol. 152, pp. 1-7, 2013.

[12] B. Perussia, Y. Chen, and M. J. Loza, "Peripheral NK cell phenotypes: multiple changing of faces of an adapting, developing cell," Molecular Immunology, vol. 42, no. 4, pp. 385-395, 2005.

[13] M. A. Degli-Esposti and M. J. Smyth, "Close encounters of different kinds: dendritic cells and NK cells take centre stage," Nature Reviews Immunology, vol. 5, no. 2, pp. 112-124, 2005. 
[14] S. H. Robbins, G. Bessou, A. Cornillon et al., "Natural killer cells promote early CD8 T cell responses against cytomegalovirus," PLoS Pathogens, vol. 3, no. 8, article e123, 2007.

[15] D. Rudnicka, A. Oszmiana, D. K. Finch et al., "Rituximab causes a polarization of $\mathrm{B}$ cells that augments its therapeutic function in NK-cell-mediated antibody-dependent cellular cytotoxicity," Blood, vol. 121, pp. 4694-4702, 2013.

[16] M. C. López, B. E. Palmer, and D. A. Lawrence, "Phenotypic differences between cord blood and adult peripheral blood," Cytometry Part B, vol. 76, no. 1, pp. 37-46, 2009.

[17] T. W. Chin, B. J. Ank, and D. Murakami, "Cytotoxic studies in human newborns: lessened allogeneic cell-induced (augmented) cytotoxicity but strong lymphokine-activated cytotoxicity of cord mononuclear cells," Cellular Immunology, vol. 103, no. 2, pp. 241-251, 1986.

[18] J. D. Peoples, S. Cheung, M. Nesin et al., "Neonatal cord blood subsets and cytokine response to bacterial antigens," American Journal of Perinatology, vol. 26, no. 9, pp. 647-657, 2009.

[19] J. Gaddy and H. E. Broxmeyer, "Cord blood CD16 $56^{-}$cells with low lytic activity are possible precursors of mature natural killer cells," Cellular Immunology, vol. 180, no. 2, pp. 132-142, 1997.

[20] J.-H. Dalle, J. Menezes, É. Wagner et al., "Characterization of cord blood natural killer cells: implications for transplantation and neonatal infections," Pediatric Research, vol. 57, no. 5, pp. 649-655, 2005.

[21] H. Tanaka, S. Kai, M. Yamaguchi et al., "Analysis of natural killer (NK) cell activity and adhesion molecules on NK cells from umbilical cord blood," European Journal of Haematology, vol. 71, no. 1, pp. 29-38, 2003.

[22] S. Lopez-Vergès, J. M. Milush, S. Pandey et al., "CD57 defines a functionally distinct population of mature NK cells in the human CD56dimCD16 ${ }^{+}$NK-cell subset," Blood, vol. 116, no. 19, pp. 3865-3874, 2010.

[23] M. Luevano, M. Daryouzeh, R. Alnabhan et al., "The unique profile of cord blood natural killer cells balances incomplete maturation and effective killing function upon activation," Human Immunology, vol. 73, no. 3, pp. 248-257, 2012.

[24] S.-J. Lin and M.-L. Kuo, "Effect of cyclosporin A on interleukin15-activated umbilical cord blood natural killer cell function," Cytotherapy, vol. 10, no. 4, pp. 397-405, 2008.

[25] S.-J. Lin and D.-C. Yan, "ICAM-1 (CD54) expression on T lymphocytes and natural killer cells from umbilical cord blood: regulation with interleukin-12 and interleukin-15," Cytokines, Cellular and Molecular Therapy, vol. 6, no. 4, pp. 161-164, 2000.

[26] S.-J. Lin, P.-J. Cheng, T.-Y. Lin, P.-T. Lee, H.-S. Hsiao, and M.L. Kuo, "Effect of influenza a infection on umbilical cord blood natural killer function regulation with interleukin-15," Journal of Infectious Diseases, vol. 205, no. 5, pp. 745-756, 2012.

[27] Y. Sundström, C. Nilsson, G. Lilja, K. Kärre, M. TroyeBlomberg, and L. Berg, "The expression of human natural killer cell receptors in early life," Scandinavian Journal of Immunology, vol. 66, no. 2-3, pp. 335-344, 2007.

[28] Y. Wang, H. Xu, X. Zheng, H. Wei, R. Sun, and Z. Tian, "High expression of NKG2A/CD94 and low expression of granzyme B are associated with reduced cord blood NK cell activity," Cellular \& Molecular Immunology, vol. 4, no. 5, pp. 377-382, 2007.

[29] P. M. Sondel and K. L. Alderson, "Clinical cancer therapy by NK cells via antibody-dependent cell-mediated cytotoxicity," Journal of Biomedicine and Biotechnology, vol. 2011, Article ID 379123, 2011.
[30] S.-J. Lin, M.-H. Yang, H.-C. Chao, M.-L. Kou, and J.-L. Huang, "Effect of interleukin-15 and Flt3-ligand on natural killer cell expansion and activation: umbilical cord vs. adult peripheral blood mononuclear cell," Pediatric Allergy and Immunology, vol. 11, no. 3, pp. 168-174, 2000.

[31] S. S. Choi, V. S. Chhabra, Q. H. Nguyen, B. J. Ank, E. R. Stiehm, and R. L. Roberts, "Interleukin-15 enhances cytotoxicity, receptor expression, and expansion of neonatal natural killer cells in long-term culture," Clinical and Diagnostic Laboratory Immunology, vol. 11, no. 5, pp. 879-888, 2004.

[32] I. Engelmann, U. Moeller, A. Santamaria, P. G. Kremsner, and A. J. F. Luty, "Differing activation status and immune effector molecule expression profiles of neonatal and maternal lymphocytes in an African population," Immunology, vol. 119, no. 4, pp. 515-521, 2006.

[33] D. Xing, A. G. Ramsay, J. G. Gribben et al., "Cord blood natural killer cells exhibit impaired lytic immunological synapse formation that is reversed with il-2 exvivo expansion," Journal of Immunotherapy, vol. 33, no. 7, pp. 684-696, 2010.

[34] S.-J. Lin, P.-J. Cheng, Y.-J. Huang, and M.-L. Kuo, "Evaluation of cytotoxic function and apoptosis in interleukin (IL)-12/IL-15treated umbilical cord or adult peripheral blood natural killer cells by a propidium-iodide based flow cytometry," Pediatric Allergy and Immunology, vol. 15, no. 1, pp. 79-85, 2004.

[35] M. Krampera, L. Tavecchia, F. Benedetti, G. Nadali, and G. Pizzolo, "Intracellular cytokine profile of cord blood T-, and NK- cells and monocytes," Haematologica, vol. 85, no. 7, pp. 675-679, 2000.

[36] A. S. Lau, M. Sigaroudinia, M. C. Yeung, and S. Kohl, "Interleukin-12 induces interferon- $\gamma$ expression and natural killer cytotoxicity in cord blood mononuclear cells," Pediatric Research, vol. 39, no. 1, pp. 150-155, 1996.

[37] A. Nomura, H. Takada, C.-H. Jin, T. Tanaka, S. Ohga, and T. Hara, "Functional analyses of cord blood natural killer cells and T cellsa distinctive interleukin-18 response," Experimental Hematology, vol. 29, no. 10, pp. 1169-1176, 2001.

[38] J. M. Palmer, K. Rajasekaran, M. S. Thakar, and S. Malarkannan, "Clinical relevance of natural killer cells following hematopoietic stem cell transplantation," Journal of Cancer, vol. 4, pp. 2535, 2013.

[39] C. H. Tay, E. Szomolanyi-Tsuda, and R. M. Welsh, "Control of infections by NK cells," Current Topics in Microbiology and Immunology, vol. 230, pp. 193-220, 1998.

[40] C. A. Biron, K. B. Nguyen, G. C. Pien, L. P. Cousens, and T. P. Salazar-Mather, "Natural killer cells in antiviral defense: function and regulation by innate cytokines," Annual Review of Immunology, vol. 17, pp. 189-220, 1999.

[41] A. Poli, T. Michel, M. Thérésine, E. Andrès, F. Hentges, and J. Zimmer, "CD56bright natural killer (NK) cells: an important NK cell subset," Immunology, vol. 126, no. 4, pp. 458-465, 2009.

[42] T. A. Fehniger, M. A. Cooper, G. J. Nuovo et al., "CD56bright natural killer cells are present in human lymph nodes and are activated by $\mathrm{T}$ cell-derived IL-2: a potential new link between adaptive and innate immunity," Blood, vol. 101, no. 8, pp. 30523057, 2003.

[43] A. Moretta, M. Vitale, C. Bottino et al., "P58 molecules as putative receptors for major histocompatibility complex (MHC) class I molecules in human natural killer (NK) cells. Antip58 antibodies reconstitute lysis of MHC class I-protected cells in NK clones displaying different specificities," Journal of Experimental Medicine, vol. 178, no. 2, pp. 597-604, 1993. 
[44] A. Moretta, C. Bottino, M. Vitale et al., "Receptors for HLA class-I molecules in human natural killer cells," Annual Review of Immunology, vol. 14, pp. 619-648, 1996.

[45] S. Sivori, D. Pende, C. Bottino et al., "NKp46 is the major triggering receptor involved in the natural cytotoxicity of fresh or cultured human NK cells. Correlation between surface density of NKp46 and natural cytotoxicity against autologous, allogeneic or xenogeneic target cells," European Journal of Immunology, vol. 29, pp. 1656-1666, 1999.

[46] O. Mandelboim, N. Lieberman, M. Lev et al., "Recognition of haemagglutinins on virus-infected cells by NKp46 activates lysis by human NK cells," Nature, vol. 409, no. 6823, pp. 10551060, 2001.

[47] M. Jinushi, T. Takehara, T. Tatsumi et al., "Negative regulation of NK cell activities by inhibitory receptor CD94/NKG2A leads to altered NK cell-induced modulation of dendritic cell functions in chronic hepatitis C virus infection," Journal of Immunology, vol. 173, no. 10, pp. 6072-6081, 2004.

[48] G. Ferlazzo, M. L. Tsang, L. Moretta, G. Melioli, R. M. Steinman, and C. Münz, "Human dendritic cells activate resting natural killer (NK) cells and are recognized via the NKp30 receptor by activated NK cells," Journal of Experimental Medicine, vol. 195, no. 3, pp. 343-351, 2002.

[49] L. Zitvogel, "Dendritic and natural killer cells cooperate in the control/switch of innate immunity," Journal of Experimental Medicine, vol. 195, no. 3, pp. F9-F14, 2002.

[50] L. G. Guidotti and F. V. Chisari, "Noncytolytic control of viral infections by the innate and adaptive immune response," Annual Review of Immunology, vol. 19, pp. 65-91, 2001.

[51] T. P. Salazar-Mather, C. A. Lewis, and C. A. Biron, “Type I interferons regulate inflammatory cell trafficking and macrophage inflammatory protein $1 \alpha$ delivery to the liver," Journal of Clinical Investigation, vol. 110, no. 3, pp. 321-330, 2002.

[52] M. A. Pak-Wittel, L. Yang, D. K. Sojka, J. G. Rivenbark, and W. M. Yokoyama, "Interferon- $\gamma$ mediates chemokine-dependent recruitment of natural killer cells during viral infection," Proceedings of the National Academy of Sciences of the United States of America, vol. 110, pp. E50-E59, 2013.

[53] J. S. Orange, "Human natural killer cell deficiencies and susceptibility to infection," Microbes and Infection, vol. 4, no. 15, pp. 1545-1558, 2002.

[54] G. Fleisher, S. Starr, and N. Koven, "A non-X-linked syndrome with susceptibility to severe Epstein-Barr virus infections," Journal of Pediatrics, vol. 100, no. 5, pp. 727-730, 1982.

[55] S. Kim, J. B. Sunwoo, L. Yang et al., "HLA alleles determine differences in human natural killer cell responsiveness and potency," Proceedings of the National Academy of Sciences of the United States of America, vol. 105, no. 8, pp. 3053-3058, 2008.

[56] S. Cooley, F. Xiao, M. Pitt et al., "A subpopulation of human peripheral blood NK cells that lacks inhibitory receptors for self-MHC is developmentally immature," Blood, vol. 110, no. 2, pp. 578-586, 2007.

[57] S. Kim, J. Poursine-Laurent, S. M. Truscott et al., "Licensing of natural killer cells by host major histocompatibility complex class I molecules," Nature, vol. 436, no. 7051, pp. 709-713, 2005.

[58] K. Schönberg, J. C. Fischer, G. Kögler, and M. Uhrberg, "Neonatal NK-cell repertoires are functionally, but not structurally, biased toward recognition of self HLA class I," Blood, vol. 117, no. 19, pp. 5152-5156, 2011.
[59] M. Gumá, A. Angulo, C. Vilches, N. Gómez-Lozano, N. Malats, and M. López-Botet, "Imprint of human cytomegalovirus infection on the NK cell receptor repertoire," Blood, vol. 104, no. 12, pp. 3664-3671, 2004.

[60] H. N. Charoudeh, G. Terszowski, K. Czaja, A. Gonzalez, K. Schmitter, and M. Stern, "Modulation of the natural killer cell KIR repertoire by cytomegalovirus infection," European Journal of Immunology, vol. 43, pp. 480-487, 2013.

[61] A. Monsiváis-Urenda, D. Noyola-Cherpitel, A. HernándezSalinas et al., "Influence of human cytomegalovirus infection on the NK cell receptor repertoire in children," European Journal of Immunology, vol. 40, pp. 1418-1427, 2010.

[62] C. Tomescu, S. Abdulhaqq, and L. J. Montaner, "Evidence for the innate immune response as a correlate of protection in human immunodeficiency virus (HIV)-1 highly exposed seronegative subjects (HESN)," Clinical and Experimental Immunology, vol. 164, no. 2, pp. 158-169, 2011.

[63] S.-J. Lin, R. L. Roberts, B. J. Ank, Q. H. Nguyen, E. K. Thomas, and E. R. Stiehm, "Effect of interleukin (IL)-12 and IL-15 on activated natural killer (ANK) and antibody-dependent cellular cytotoxicity (ADCC) in HIV infection," Journal of Clinical Immunology, vol. 18, no. 5, pp. 335-345, 1998.

[64] S.-J. Lin, R. L. Roberts, B. J. Ank, Q. H. Nguyen, E. K. Thomas, and E. R. Stiehm, "Human immunodeficiency virus (HIV) type-1 GP120-specific cell-mediated cytotoxicity (CMC) and natural killer (NK) activity in HIV-infected (HIV+) subjects: enhancement with interleukin-2(IL-2), IL-12, and IL-15," Clinical Immunology and Immunopathology, vol. 82, no. 2, pp. 163173, 1997.

[65] V. Naranbhai, M. Altfeld, S. S. Karim, T. Ndung’u, Q. A. Karim, and W. H. Carr, "Changes in Natural Killer cell activation and function during primary HIV-1 Infection," PLOS ONE, vol. 8, Article ID e53251, 2013.

[66] F. R. Guerini and M. Clerici, "NK cells in human disease: an evolving story," Clinical Immunology, vol. 143, no. 3, pp. 203206, 2012.

[67] W. M. Ballan, B.-A. N. Vu, B. R. Long et al., "Natural killer cells in perinatally HIV-1-infected children exhibit less degranulation compared to HIV-1-exposed uninfected children and their expression of KIR2DL3, NKG2C, and NKp46 correlates with disease severity," Journal of Immunology, vol. 179, no. 5, pp. 3362-3370, 2007.

[68] J. Zaunders and D. van Bockel, "Innate and adaptive immunity in long-term non-progression in HIV Disease," Frontiers in Immunology, vol. 4, article 95, 2013.

[69] A. Soria, F. R. Guerini, A. Bandera et al., "KIR-HLA genotypes in HIV-infected patients lacking immunological recovery despite effective antiretroviral therapy," PLoS ONE, vol. 6, no. 11, Article ID e27349, 2011.

[70] S. Kottilil, K. Shin, M. Planta et al., "Expression of chemokine and inhibitory receptors on natural killer cells: effect of immune activation and HIV viremia," Journal of Infectious Diseases, vol. 189, no. 7, pp. 1193-1198, 2004.

[71] A. Oliva, A. L. Kinter, M. Vaccarezza et al., "Natural killer cells from human immunodeficiency virus (HIV)-infected individuals are an important source of CC-chemokines and suppress HIV-1 entry and replication in vitro," Journal of Clinical Investigation, vol. 102, no. 1, pp. 223-231, 1998.

[72] H. B. Bernstein, A. L. Kinter, R. Jackson, and A. S. Fauci, "Neonatal natural killer cells produce chemokines and suppress HIV replication in vitro," AIDS Research and Human Retroviruses, vol. 20, no. 11, pp. 1189-1195, 2004. 
[73] A. Jacobson, F. Bell, N. Lejarcegui, C. Mitchell, L. Frenkel, and H. Horton, "Healthy neonates possess a CD56-negative NK cell population with reduced anti-viral activity," PLoS ONE, vol. 8, Article ID e67700, 2013.

[74] M. L. Heltzer, S. E. Coffin, K. Maurer et al., "Immune dysregulation in severe influenza," Journal of Leukocyte Biology, vol. 85, no. 6, pp. 1036-1043, 2009.

[75] L. Denney, C. Aitken, C. K.-F. Li et al., "Reduction of natural killer but not effector CD8 T lymphoyctes in three consecutive cases of severe/lethal H1N1/09 influenza a virus infection," PLoS ONE, vol. 5, no. 5, Article ID e10675, 2010.

[76] H. Mao, W. Tu, G. Qin et al., "Influenza virus directly infects human natural killer cells and induces cell apoptosis," Journal of Virology, vol. 83, no. 18, pp. 9215-9222, 2009.

[77] H. S. Izurieta, W. W. Thompson, P. Kramarz et al., "Influenza and the rates of hospitalization for respiratory disease among infants and young children," The New England Journal of Medicine, vol. 342, no. 4, pp. 232-239, 2000.

[78] S. E. Coffin, T. E. Zaoutis, A. B. W. Rosenquist et al., "Incidence, complications, and risk factors for prolonged stay in children hospitalized with community-acquired influenza," Pediatrics, vol. 119 , no. 4, pp. 740-748, 2007.

[79] K. H. Grabstein, J. Eisenman, K. Shanebeck et al., "Cloning of a $\mathrm{T}$ cell growth factor that interacts with the $\beta$ chain of the interleukin-2 receptor," Science, vol. 264, no. 5161, pp. 965-968, 1994.

[80] W. E. Carson, T. A. Fehniger, S. Haldar et al., "A potential role for interleukin-15 in the regulation of human natural killer cell survival," Journal of Clinical Investigation, vol. 99, no. 5, pp. 937943, 1997.

[81] T. Ranson, C. A. J. Vosshenrich, E. Corcuff, O. Richard, W. Müller, and J. P. Di Santo, "IL-15 is an essential mediator of peripheral NK-cell homeostasis," Blood, vol. 101, no. 12, pp. 4887-4893, 2003.

[82] J.-X. Lin, T.-S. Migone, M. Tsang et al., "The role of shared receptor motifs and common stat proteins in the generation of cytokine pleiotropy and redundancy by IL-2, IL-4, IL-7, IL-13, and IL-15," Immunity, vol. 2, no. 4, pp. 331-339, 1995.

[83] D. De Totero, R. Meazza, M. Capaia et al., "The opposite effects of IL-15 and IL-21 on CLL B cells correlate with differential activation of the JAK/STAT and ERK1/2 pathways," Blood, vol. 111, no. 2, pp. 517-524, 2008.

[84] J. X. Qian, S. M. Lee, Y. Suen, E. Knoppel, C. Van De Ven, and M. S. Cairo, "Decreased interleukin-15 from activated cord versus adult peripheral blood mononuclear cells and the effect of interleukin-15 in upregulating antitumor immune activity and cytokine production in cord blood," Blood, vol. 90, no. 8, pp. 3106-3117, 1997.

[85] N. L. Alves, B. Hooibrink, F. A. Arosa, and R. A. W. Van Lier, "IL15 induces antigen-independent expansion and differentiation of human naive $\mathrm{CD} 8^{+}$T cells in vitro," Blood, vol. 102, no. 7, pp. 2541-2546, 2003.

[86] Y. Li, W. Zhi, P. Wareski, and N.-P. Weng, "IL-15 activates telomerase and minimizes telomere loss and may preserve the replicative life span of memory $\mathrm{CD}^{+} \mathrm{T}$ cells in vitro," Journal of Immunology, vol. 174, no. 7, pp. 4019-4024, 2005.

[87] N. Gill, K. L. Rosenthal, and A. A. Ashkar, "NK and NKT cellindependent contribution of interleukin-15 to innate protection against mucosal viral infection," Journal of Virology, vol. 79, no. 7, pp. 4470-4478, 2005.
[88] Y. Kagimoto, H. Yamada, T. Ishikawa et al., "A regulatory role of interleukin 15 in wound healing and mucosal infection in mice," Journal of Leukocyte Biology, vol. 83, no. 1, pp. 165-172, 2008.

[89] Y. M. Mueller, P. M. Bojczuk, E. S. Halstead et al., "IL-15 enhances survival and function of HIV-specific CD8 ${ }^{+}$T cells," Blood, vol. 101, no. 3, pp. 1024-1029, 2003.

[90] G. D’Ettorre, G. Forcina, M. Lichtner et al., "Interleukin-15 in HIV infection: immunological and virological interactions in antiretroviral-naive and -treated patients," AIDS, vol. 16, no. 2, pp. 181-188, 2002. 


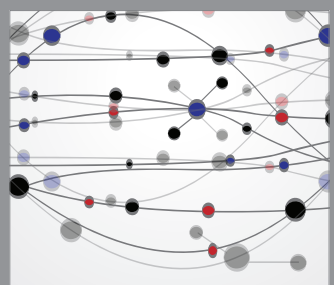

The Scientific World Journal
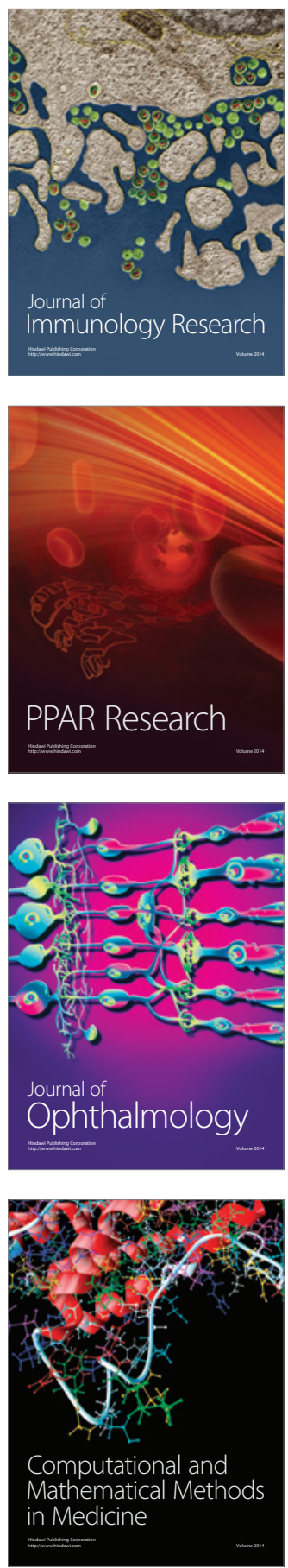

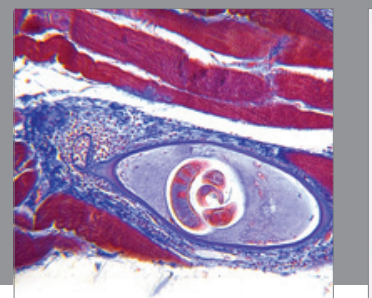

Gastroenterology

Research and Practice
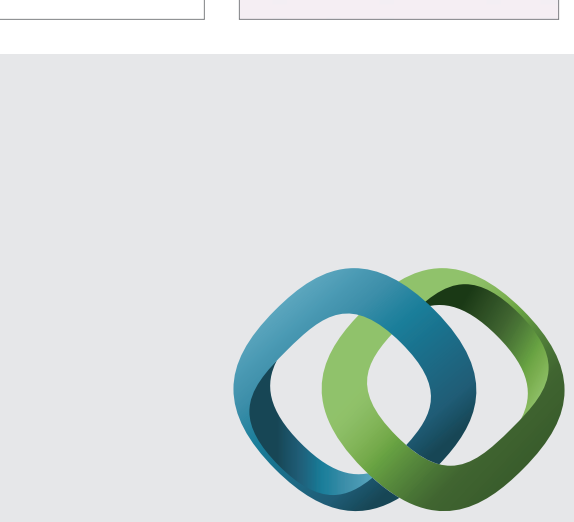

\section{Hindawi}

Submit your manuscripts at

http://www.hindawi.com
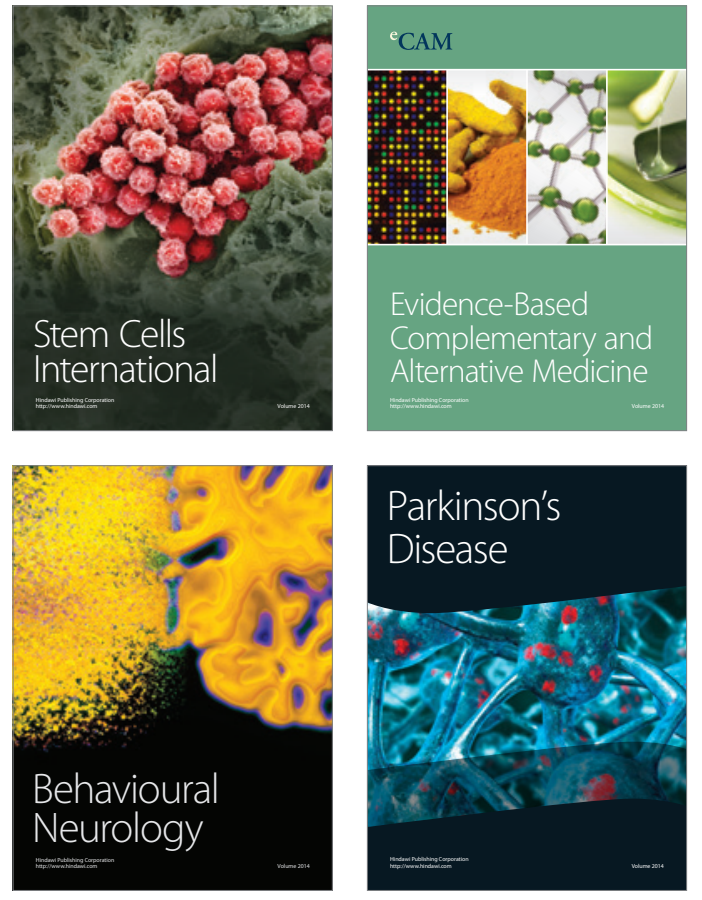
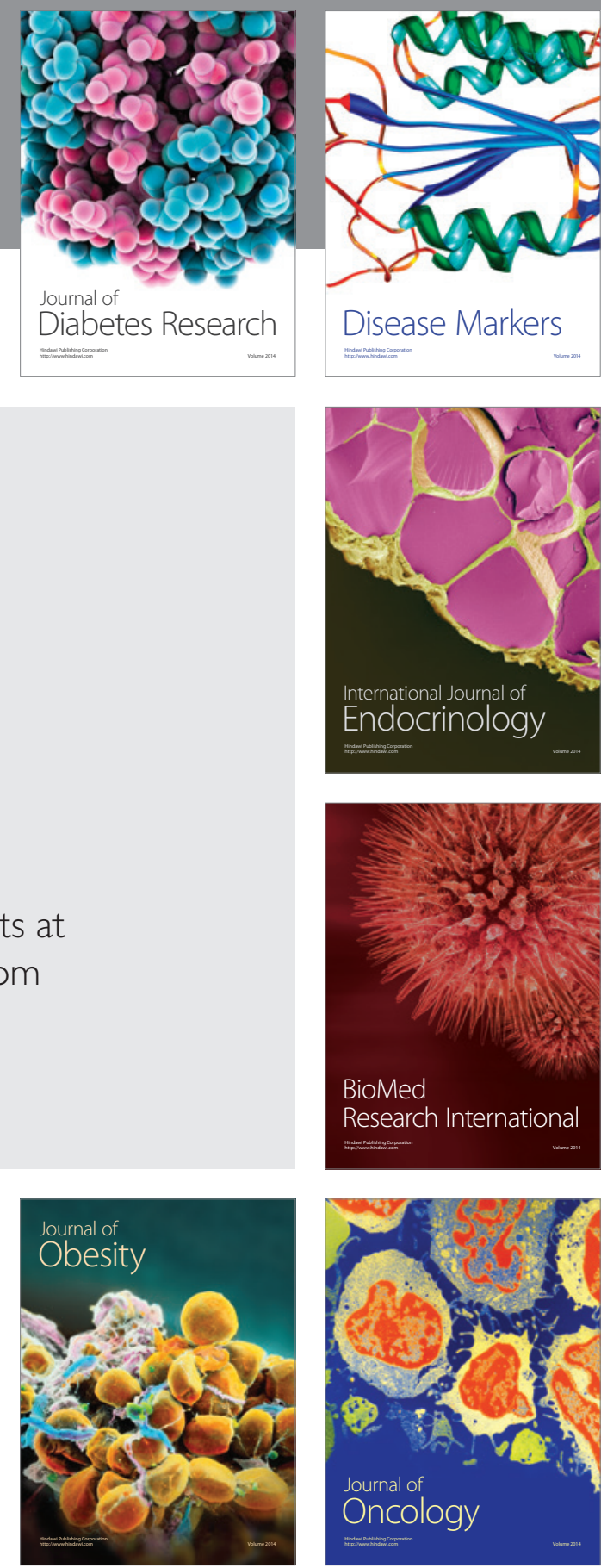

Disease Markers
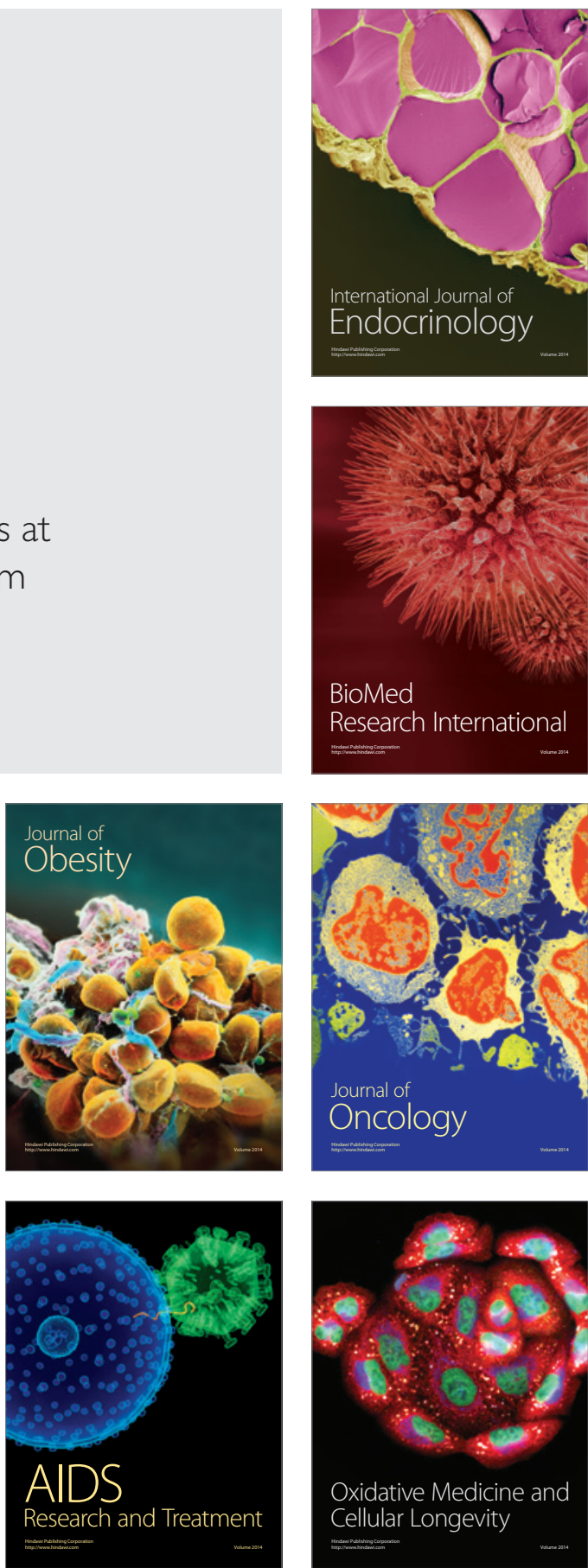